\title{
IR study of Pb-Sr titanate borosilicate glasses
}

\author{
C R GAUTAM*, DEVENDRA KUMAR ${ }^{\dagger}$ and OM PARKASH ${ }^{\dagger}$ \\ Department of Physics, University of Lucknow, Lucknow 226 007, India \\ ${ }^{\dagger}$ Department of Ceramic Engineering, Institute of Technology, Banaras Hindu University, Varanasi 221 005, India
}

MS received 3 January 2009; revised 18 March 2009

\begin{abstract}
The infrared spectra (IR) of various glass compositions in the glass system, $\left[\left(\mathrm{Pb}_{x} \mathrm{Sr}_{1-x}\right) \mathbf{O} \cdot \mathrm{TiO}_{2}\right]-$ $\left[2 \mathrm{SiO}_{2} \cdot \mathrm{B}_{2} \mathrm{O}_{3}\right]-\left[\mathrm{BaO} \cdot \mathrm{K}_{2} \mathrm{O}\right]-\left[\mathrm{La}_{2} \mathrm{O}_{3}\right]$, were recorded over a continuous spectral range $\left(400-4000 \mathrm{~cm}^{-1}\right)$ to study their structure systematically. IR spectrum of each glass composition shows a number of absorption bands. These bands are strongly influenced by the increasing substitution of $\mathrm{SrO}$ for $\mathrm{PbO}$. Various bands shift with composition. Absorption peaks occur due to the vibrational mode of the borate network in these glasses. The vibrational modes of the borate network are seen to be mainly due to the asymmetric stretching relaxation of the $\mathrm{B}-\mathrm{O}$ bond of trigonal $\mathrm{BO}_{3}$ units. More splitting is observed in strontium-rich composition.
\end{abstract}

Keywords. Lead strontium titanate borosilicate glasses; infrared spectroscopy.

\section{Introduction}

The infrared spectroscopy has been used since a long time to investigate the structure of different glasses (Kamitsos et al 1987). This technique is most readily seen as contributing to the knowledge of structure and chemical bonding in various glasses (Gautam 2005). Alkali borate glasses are an ideal case in comparison to other glass forming systems to demonstrate the effectiveness of the spectroscopic technique in glass science. Borate glasses, in particular, have been the subject of numerous infrared studies due to their structural peculiarities (Wong and Angell 1976; Kamitsos and Karakassides 1989). In borate glasses, $\mathrm{B}_{2} \mathrm{O}_{3}$ is a basic glass former because of its higher bond strength, lower cation size, and small heat of fusion. In these glasses, $\mathrm{B}^{3+}$ ions are triangularly coordinated by oxygen. $\mathrm{B}_{2} \mathrm{O}_{3}$ units are corner bonded in a random configuration (Yawale et al 2000). The structure of borate glasses heavily depend upon the cooling rate of the melt through the range of glass transition temperature (Soppe and Marel 1988). Lead oxide and strontium oxide can enter the glass both as a network former and also as a network modifier. Due to this nature of $\mathrm{PbO}$ and $\mathrm{SrO}$, the structure of these glasses are expected to be different from that of alkali borate, phosphate and silicate glasses. In the present investigation, glasses in the system $\left[\left(\mathrm{Pb}_{x} \mathrm{Sr}_{1-x}\right) \mathrm{OTiO}_{2}\right]-$ $\left[2 \mathrm{SiO}_{2} \cdot \mathrm{B}_{2} \mathrm{O}_{3}\right]-\left[\mathrm{K}_{2} \mathrm{O}\right]-[\mathrm{BaO}]-\left[\mathrm{La}_{2} \mathrm{O}_{3}\right]$ with varying lead to strontium ratios $(0 \leq x \leq 1.0)$ have been prepared. All the glass samples were found to be completely amorphous in

*Author for correspondence (gautam_ceramic@yahoo.com) nature. Various glass ceramic samples were prepared by crystallizing different glasses on the basis of their differential thermal analysis (DTA). XRD patterns of lead-rich glass ceramic samples confirm the formation of tetragonal perovskite crystals similar to lead titanate as major phase. Additional large numbers of peaks were found in the XRD patterns of the lead-rich glass ceramic samples due to the formation of $\mathrm{PbTi}_{3} \mathrm{O}_{7}$ as a secondary phase. XRD patterns of strontium-rich glass ceramic samples show small number of peaks and structure was found to be cubic unit cell similar to strontium titanate (Kumar et al 2006). The difference in the crystallization behaviour of lead-rich and strontium-rich glasses indicates that the structure of glasses changes with changing lead/strontium ratio in the glass.

In this paper, the objective was to explore the structure of lead strontium titanate borosilicate glasses containing varying ratios of $\mathrm{PbO} / \mathrm{SrO}$ using infrared spectroscopy. This will help in understanding the crystallization behaviour of these glasses.

\section{Experimental}

\subsection{Sample preparation}

Glasses in the system, $\left[\left(\mathrm{Pb}_{x} \mathrm{Sr}_{1-x}\right) \mathrm{OTiO}_{2}\right]-\left[2 \mathrm{SiO}_{2} \cdot \mathrm{B}_{2} \mathrm{O}_{3}\right]-$ $\left[\mathrm{K}_{2} \mathrm{O}\right]-[\mathrm{BaO}]-\left[\mathrm{La}_{2} \mathrm{O}_{3}\right]$, with varying lead to strontium ratios $(0 \leq x \leq 1 \cdot 0)$ have been prepared by melt quench method. Appropriate amounts of highly pure chemicals, $\mathrm{PbO}$ (Aldrich, 99\%), $\mathrm{SrCO}_{3}$ (Aldrich, 99.9\%), $\mathrm{TiO}_{2}$ (Aldrich, 99.9\%), $\mathrm{SiO}_{2}(\mathrm{CDH}, 99 \%), \mathrm{H}_{3} \mathrm{BO}_{3}$ (Glaxo, 99.5\%), $\mathrm{BaCO}_{3}(\mathrm{CDH}, 99.5 \%), \mathrm{K}_{2} \mathrm{CO}_{3}(\mathrm{CDH}, 99.9 \%)$ and $\mathrm{La}_{2} \mathrm{O}_{3}$ (Aldrich, 99.99\%) were intimately mixed in 
acetone in an agate mortar and pestle until they dried. The dry powders were melted in the temperature range $1120-1290^{\circ} \mathrm{C}$ in an electrically heated furnace. The melt was poured into an aluminium mould, pressed by a thick aluminium plate and immediately annealed at $300^{\circ} \mathrm{C}$ for $3 \mathrm{~h}$ in another furnace. Infrared absorption spectra of the powdered glass samples mixed with $\mathrm{KBr}$ powder and pressed as pellets were recorded using JASCO FT/IR5300 in the wave number range $400-4000 \mathrm{~cm}^{-1}$ at room temperature. IR spectra of various glass samples show the absorption band with different frequencies. In our lead strontium titanate borosilicate glass systems, some of the glass compositions depict the change in the glass structure. The various bands are recorded with respect to different stretching vibrations.

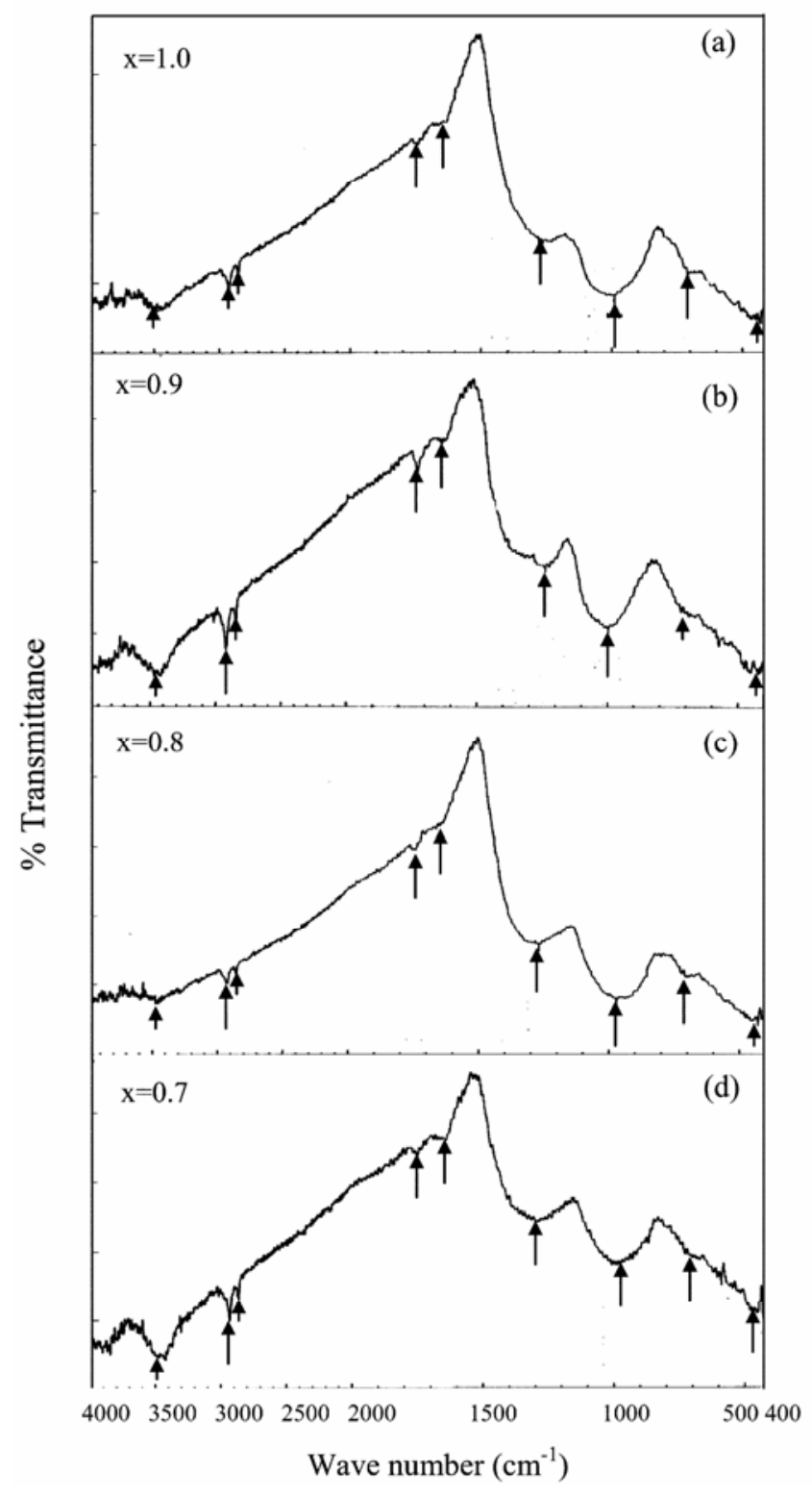

Figure 1. Infrared spectra of glasses (a) PTL5B, $x=1 \cdot 0$, (b) 9PL5B, $x=0 \cdot 9$, (c) 8PL5B, $x=0.8$ and (d) 7PL5B, $x=0.7$.

\subsection{Nomenclature of glass samples}

Five letters glass code refers to the composition of the glass. First two letters PT, 9P etc designate the fraction of lead i.e. $x$ in the glass. PT refers to $x=1.0$ i.e. $100 \%$ lead $(\mathrm{Pb})$ and $0 \%$ strontium. 9P, 8P etc refers to $x=0.9,0 \cdot 8$, respectively. The third letter $\mathrm{L}$ indicates that $\mathrm{La}_{2} \mathrm{O}_{3}$ is used as an additive. The last two letters $5 \mathrm{~B}$ refer to fraction of modifier oxides $\mathrm{BaO}$ in the parent glass compositions.

\section{Results and discussion}

The infrared (IR) spectra for all the glasses are shown in figures 1, 2 and 3, respectively. The IR spectra of these

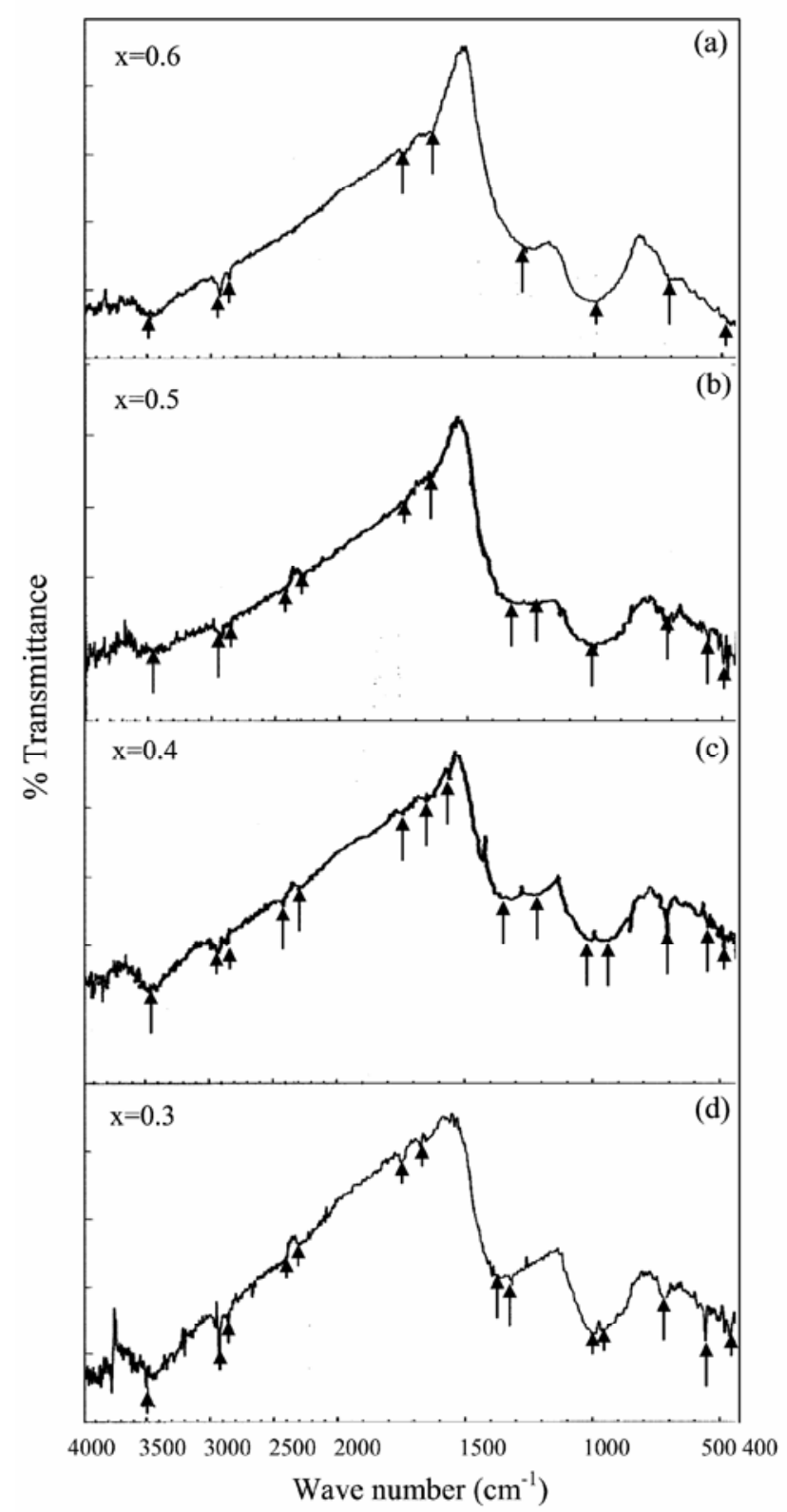

Figure 2. Infrared spectra of glasses (a) 6PL5B, $x=0 \cdot 6$, (b) 5PL5B, $x=0 \cdot 5$, (c) 4PL5B, $x=0 \cdot 4$ and (d) 3PL5B, $x=0 \cdot 3$. 
Table 1. Wavelengths of different absorption peaks in FTIR spectra of the glasses in the system $\left[\left(\mathrm{Pb}_{x} \mathrm{Sr}_{1-x}\right) \mathrm{O} \cdot \mathrm{TiO}_{2}\right]-$ $\left[2 \mathrm{SiO}_{2} \cdot \mathrm{B}_{2} \mathrm{O}_{3}\right]-\left[\mathrm{BaO} \cdot \mathrm{K}_{2} \mathrm{O}\right]-\left[\mathrm{La}_{2} \mathrm{O}_{3}\right]$.

\begin{tabular}{|c|c|c|c|c|c|c|c|c|c|c|c|c|c|c|c|c|}
\hline \multirow[b]{3}{*}{ Glass codes } & \multirow[b]{3}{*}{$x$} & \multicolumn{15}{|c|}{ Wave numbers of different absorption peaks $\left(\mathrm{cm}^{-1}\right)$} \\
\hline & & \multirow[b]{2}{*}{1} & \multicolumn{2}{|c|}{2} & \multicolumn{2}{|c|}{3} & \multirow[b]{2}{*}{4} & \multirow[b]{2}{*}{5} & \multirow[b]{2}{*}{6} & \multirow{2}{*}{\multicolumn{2}{|c|}{7}} & \multicolumn{2}{|c|}{8} & \multirow[b]{2}{*}{9} & \multicolumn{2}{|c|}{10} \\
\hline & & & a & $\mathrm{b}$ & a & $\mathrm{b}$ & & & & & & a & b & & $\mathrm{a}$ & $\mathrm{b}$ \\
\hline PTL5B & 1.0 & 3483 & 2915 & 2890 & \multicolumn{2}{|c|}{-} & 1730 & 1650 & - & \multicolumn{2}{|c|}{1280} & \multicolumn{2}{|c|}{995} & 715 & \multicolumn{2}{|c|}{420} \\
\hline 9PL5B & 0.9 & 3472 & 2991 & 2860 & \multicolumn{2}{|c|}{-} & 1730 & 1630 & - & \multicolumn{2}{|c|}{1250} & 10 & & 725 & \multicolumn{2}{|c|}{430} \\
\hline 8PL5B & $0 \cdot 8$ & 3500 & 2990 & 2890 & \multicolumn{2}{|c|}{-} & 1730 & 1630 & - & \multicolumn{2}{|c|}{1290} & & & 730 & \multicolumn{2}{|c|}{450} \\
\hline 7PL5B & $0 \cdot 7$ & 3480 & 2925 & 2865 & \multicolumn{2}{|c|}{-} & 1750 & 1645 & - & \multirow{2}{*}{\multicolumn{2}{|c|}{$\begin{array}{l}1300 \\
1230\end{array}$}} & & & 705 & \multicolumn{2}{|c|}{460} \\
\hline 6PL5B & $0 \cdot 6$ & 3490 & 2915 & 2840 & \multicolumn{2}{|c|}{ - } & 1740 & 1638 & - & & & & & 701 & \multicolumn{2}{|c|}{480} \\
\hline 5PL5B & 0.5 & 3450 & 2925 & 2840 & 2410 & 2290 & 1740 & 1640 & - & 1310 & 1210 & \multicolumn{2}{|c|}{1000} & 703 & 550 & 480 \\
\hline 4PL5B & $0 \cdot 4$ & 3485 & 2940 & 2850 & 2420 & 2300 & 1740 & 1650 & 1575 & 1340 & 1210 & 1030 & 940 & 703 & 550 & 480 \\
\hline 3PL5B & $0 \cdot 3$ & 3500 & 2922 & 2850 & 2500 & 2300 & 1750 & 1680 & - & 1375 & 1225 & 1000 & 960 & 720 & 555 & 440 \\
\hline 2PL5B & $0 \cdot 2$ & 3500 & 2920 & 2850 & 2425 & 2280 & 1740 & 1690 & - & 1360 & 1285 & 1005 & 956 & 716 & 540 & 440 \\
\hline 1PL5B & $0 \cdot 1$ & 3501 & 2920 & 2850 & 2395 & 2305 & 1740 & 1680 & - & 1370 & 1310 & 998 & 955 & 718 & 555 & 456 \\
\hline STL5B & $0 \cdot 0$ & 3425 & 2992 & 2850 & 2425 & 2290 & 1740 & 1620 & - & 1375 & 1280 & 999 & 955 & 715 & - & 438 \\
\hline
\end{tabular}

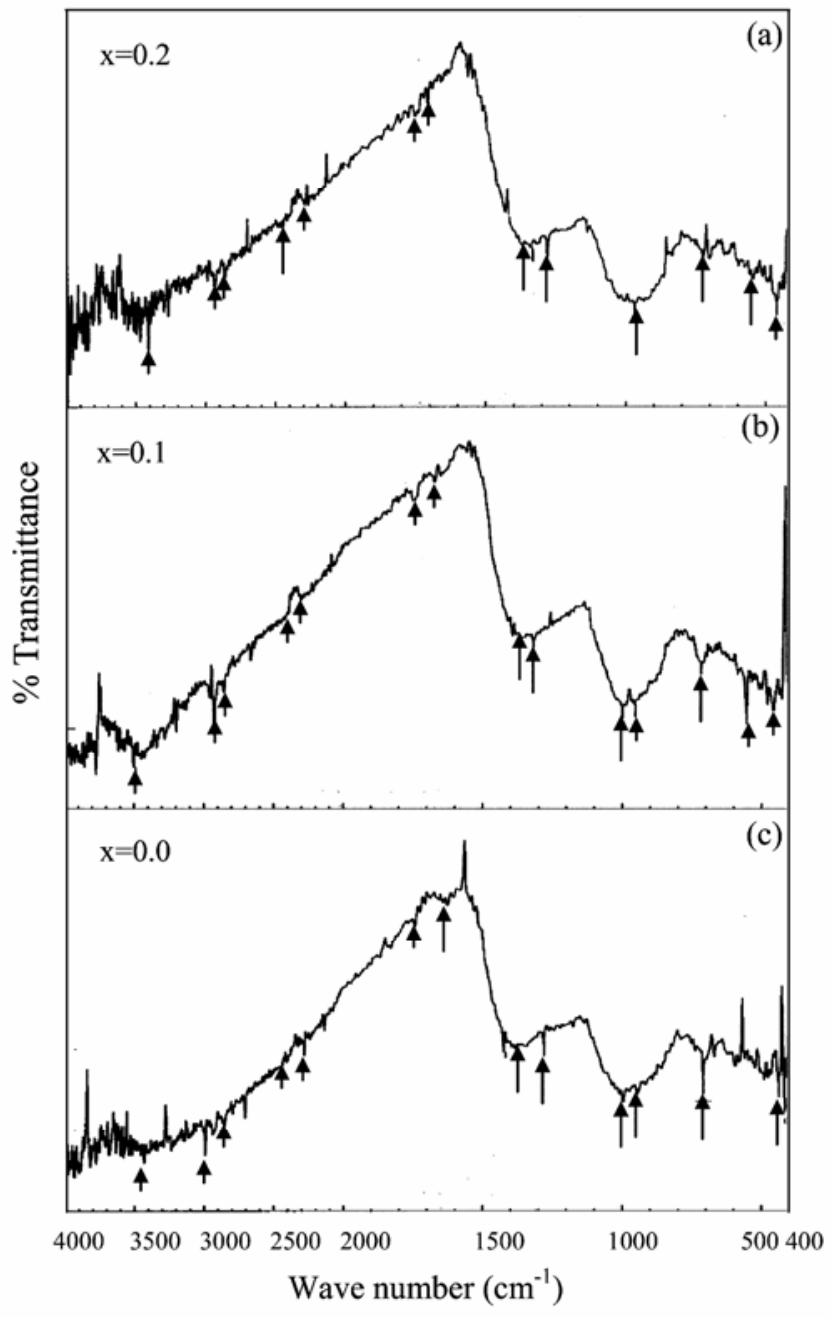

Figure 3. Infrared spectra of glasses (a) 2PL5B, $x=0 \cdot 2$, (b) 1PL5B, $x=0 \cdot 1$ and (c) STL5B, $x=0 \cdot 0$.

glasses consist of broad and sharp bands in different regions $\left(400-4000 \mathrm{~cm}^{-1}\right)$. These bands are strongly influ- enced by the increasing substitution of $\mathrm{SrO}$ for $\mathrm{PbO}$. The position of these bands shift with composition. Wavelength of different absorption peaks for all the glasses are listed in table 1. The infrared spectra of these glasses show ten absorption peaks. The peaks are sharp, medium and broad in nature. All the absorption peaks have been numbered as 1, 2, -----10 starting from high wave number side. The broad bands are exhibited in the oxide spectra, most probably due to the combination of high degeneracy of vibrational states, thermal broadening of the lattice dispersion band and mechanical scattering from powder samples. The first absorption peak lies in the range 3425$3501 \mathrm{~cm}^{-1}$. This peak is broad in lead-rich glass samples while it is sharp in strontium-rich glass samples. This is due to stretching of $\mathrm{O}-\mathrm{H}^{-}$bond inside the glassy network (Bray 1967). The O-H groups form at non-bridging oxygen sites. The peak no. 2 splits into two absorption peaks i.e. 2 ( $a$ and $b$ ). Both the peaks are very close to each other as shown in table 1. Absorption peak no. 3 is absent in the lead-rich compositions, $x=1 \cdot 0-0 \cdot 6$, while it is present in the strontium-rich compositions and split into two absorption peaks $3 \mathrm{a}$ and $3 \mathrm{~b}$.

There are a few absorption peaks in the range 1200$1750 \mathrm{~cm}^{-1}$ (peak nos 4-7) in all the glass samples. There are two absorption peak nos 4 and 5 at 1750 and $1650 \mathrm{~cm}^{-1}$ in all glass samples. Peak no. 6 is appearing only for the glass sample 4PL5B $(x=0.4)$ at $1575 \mathrm{~cm}^{-1}$. A single broad absorption peak no. 7 is observed in the glass compositions with $x=1 \cdot 0-0 \cdot 6$. The same peak splits into two peaks in all the glass compositions, which are rich in strontium. These absorption peaks occur due to the vibrational mode of the borate network. The vibrational modes of the borate network are mainly due to the asymmetric stretching relaxation of the $\mathrm{B}-\mathrm{O}$ bond of trigonal $\mathrm{BO}_{3}$ units. These vibrational modes occur at 1200-1600 cm (Kamitsos et al 1987; Eldin et al 1995; Ghoneun et al 1996). The bands at around $1000 \mathrm{~cm}^{-1}$ peak (no. 8) are attributed to a stretching vibration of 
B-O-Si linkage (Tenny and Wong 1972). A broad absorption peak (no. 9) is observed in all the IR spectra for all the glass samples. This peak lies between 685 and $709 \mathrm{~cm}^{-1}$ and is due to the bending of B-O-B linkages in the borate glassy network (Dwoeidari et al 1991). Frequency of this peak increases with increasing concentration of the SrO (table 1). The low frequency band (peak no. 10) in the IR spectra of investigated glasses can be attributed to vibration of metal cation such as $\mathrm{Pb}^{2+}$. The same band is also present in $\mathrm{PbO}-\mathrm{B}_{2} \mathrm{O}_{3}$ glass and is attributed to the vibrations of $\mathrm{Pb}^{2+}$ cations (Bray and Keefe 1963).

\section{Conclusions}

Infrared spectra of glasses in the present system show sharp and diffuse absorption peaks. These peaks occur due to different vibrational modes of the borate network of which asymmetric stretching relaxation of the $\mathrm{B}-\mathrm{O}$ bond of trigonal $\mathrm{BO}_{3}$ units contribute only. Low frequency band in the IR spectra of investigated glasses can be attributed to vibration of metal cation such as $\mathrm{Pb}^{2+}$. Strontium-rich IR spectra show more peaks in comparison to lead-rich glass spectra. Lead strontium titanate borosilicate glasses may be used for electronic applications.

\section{Acknowledgements}

Authors are highly thankful to DRDO, India, for financial support and Dr Rajesh Singh, Department of Chemistry,
Banaras Hindu University, Varanasi, for extending the IR measurements facility.

\section{References}

Bray P G 1967 Interaction of radiation with solids (New York: Plenum)

Bray P G and Keefe J G O 1963 J. Phys. Chem. Glasses 437

Dwoeidari H, Zeid Abou and Damraway E I 1991 J. Phys. D: Appl. Phys. 24222

Ezz Eldin F M, Alaily N A E L, Khalifa F A and Batal H A E L 1995 in Fundamental of glass science and technology, 3rd E.S.G. conference (Germany: Verlag Der Deutschen Glastechnischen Gesellschaft)

Gautam C R 2005 Study of crystallization, microstructure and electrical behaviour of lead strontium titanate borosilicate glass ceramics with $\mathrm{La}_{2} \mathrm{O}_{3}$ and $\mathrm{Nb}_{2} \mathrm{O}_{5}$ as additives, Ph.D. Thesis, Banaras Hindu University, Varanasi

Ghoneun N A, Batal H A E I, Abdel Shafi N and Azooz M H 1996 Proceeding of Egyptian conference of chemistry (London: Gordon and Breach Science Publishers) p 162

Kamitsos E I and Karakassides M A 1989 J. Phys. Chem. Glasses 3019

Kamitsos E I, Karakassides M A and Chryssikos G D 1987 J. Phys. Chem. Glasses 911073

Kumar D, Gautam C R and Parkash O 2006 Appl. Phys. Lett. 89 112908

Soppe W and Marel V 1988 J. Non-Cryst. Solids 103201

Tenny A S and Wong J 1972 J. Chem. Phys. 565516

Wong J and Angell C A 1976 Glass structure by spectroscopy (New York: Dekker) Ch. 7

Yawale S S, Yawale S P and Adgaonkar C S 2000 Indian J. Engg. Mater. Sci. 7150 